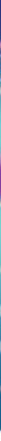

\title{
A cellular-telephone model of assessing frontal lobe function in physicians
}

\begin{abstract}
As people age, they recognize that social conduct has become worse. This is not just a failing of the young but also a reflection of modern technology, notably the cellular telephone. We observed that the behaviour induced by the use of such devices is so egregious as to be medically informative. We offer a descriptive phenomenology and neuroanatomical classification of aberrant behaviour in relation to cellular telephone use by physicians at medical conferences. Although the cellular telephone is a scourge, its ability to add to the diagnostic armamentarium in cognitive neurology should not be overlooked, especially if a fee code can be attached.
\end{abstract}

\section{$\mathrm{T}$} he cognitive function of older physicians is a matter of growing public health concern. Like everyone else, doctors are aging. In fact, if aging is understood not as time since birth but as time left before death, they are aging faster than most. This is not the tragedy it might seem: although doctors do not live as long as other people, they spend more time awake. Even so, they nap, especially at medical conferences. ${ }^{1,2}$ In consequence, the need to better understand the cognitive behaviour of physicians at medical conferences is compelling. ${ }^{3}$

How best to assess cognitive function of physicians is controversial. The Royal College of Physicians and Surgeons of Canada's Maintenance of Certification Program offers no assessment of cognitive function per se, beyond the ability to add up hours of continuing medical education. Even these simple tabulation tasks suggest that many physicians have trouble with basic arithmetic. What is more, this deficiency is so widespread as to be uninformative, although it has allowed generations of financial planners to observe that "a physician and his money are soon parted."

Technological advances, notably the cellular telephone, may be the key to assessing cognitive function in physicians. Many of the typically disruptive behaviours of people who answer cellular telephones in public are similar to the behaviours exhibited by patients with frontal lobe damage. We sought to determine whether physicians' behaviour in relation to their cellular telephone use at medical meetings would

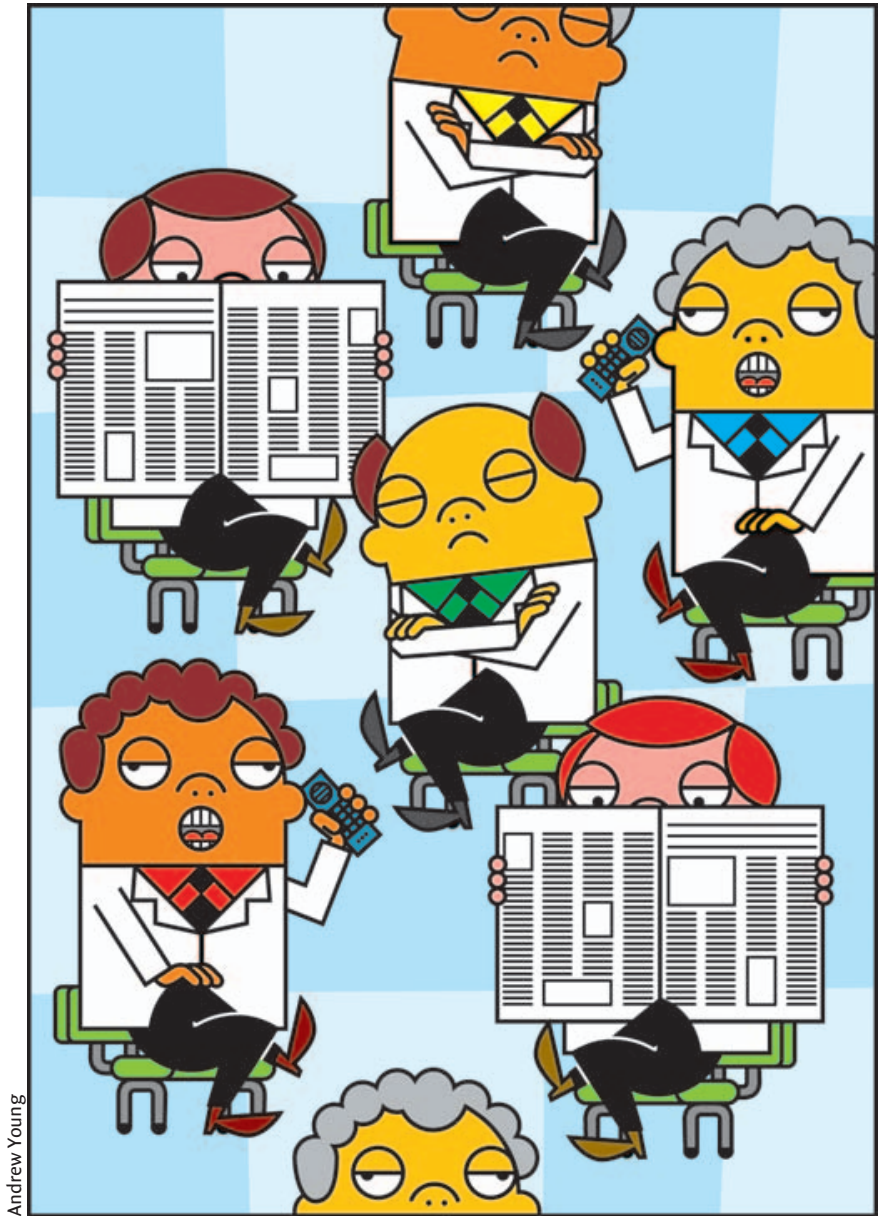

allow surreptitious assessment of their frontal lobe function, which is essential to the cognitive performance that society expects of physicians, especially older ones.

\section{Methods}

We report a qualitative observational study to achieve a descriptive phenomenology of aberrant behaviour in relation to physicians' cellular telephone use at medical conferences. We used grounded theory with iterative re- and cross-classification of observed behaviours until thematic exhaustion occurred. (Look 
it up, like we did.) Having agreed on the behaviours, we iteratively cross-classified interpretation of the phenomenon and localization of the frontal lobe dysfunction until agreement was reached.

\section{Results}

We identified 6 behaviours related to physicians' use of cellular telephones at medical conferences and the localization of the frontal lobe dysfunction (Table I). Apart from the behaviour of not bothering to answer the phone, the other behaviours tended to occur more than one at a time. Many crossed localization boundaries, which suggests that mixed dysfunction is common.

\section{Interpretation}

We have developed a novel and surreptitious means of assessing frontal lobe function in physicians on the basis of their behaviour in relation to cellular telephone use at medical conferences. The information adds to our understanding of physician behaviour at medical meetings and is an important step toward the assessment of physician competence. Although concern about physician competence is often related to aging, it need not be. Our method can be applied to physicians of all ages.

Our study had limitations. We did not use functional magnetic resonance imaging (MRI) to correlate our observations. The current state of technology does not allow for economical use of MRI-compatible cellular phones. In addition, the study was cell-phone biased. However, no one exhibiting aberrant social conduct was without a cell phone. (The converse was also often true.)

Some might object to the conceptual basis of our study. Given the increasing use of guidelines-driven models of health care delivery, much of modern medical practice ideally is decerebrate. In consequence, some degree of frontal lobe dysfunction actually aids physician cookbook compliance by minimizing intrusive so-called "clinical judgment."
We recognize, too, that our many betters at the Royal "This Is a Deadline" College will be disappointed that our approach to assessing doctors does not include confrontational testing and ritual humiliation by fully certified physicians. All we can offer in defence is that no method of physician evaluation is perfect. We hope that truly competent, busy doctors will welcome a method with such obvious face validity that makes no demand on their time and is no more invasive of their privacy than current methods of audit.

We attempted to validate our method against more traditional assessments of frontal lobe function. In keeping with the surreptitious nature of our study, we tried to work in several frontal lobe tests as part of ordinary conference conversation. (We had imagined this to be a boon; there are only so many times - no more than 3 , to be exact - that you can, in a single conversation, ask a long-ago acquaintance "So, how are you?") Often we had to retreat from such evaluation because of the high degree of frontal lobe impairment that it revealed. For example, in response to the question "How is a cauliflower like a turnip?" (a similarities question used to assess a person's conceptualization and abstract reasoning as part of the Frontal Assessment Battery ${ }^{4}$, we witnessed a range of aberrant behaviours. These included impaired social conduct (from withdrawal to verbal aggression and swearing) and echolalia (e.g., "You're a turnip!"). Similarly, requests to copy the Luria Hand Sequence Task ("Fist, Slap, Side") typically resulted in intrusion of a stereotyped hand-raising/ middle finger response (which we scored as "4" — equivalent to greatest impairment on that item).

We were split on whether reading the newspaper during a presentation was a sign of frontal lobe dysfunction. However, because academic rivalries are so common and because obvious disdain for what a speaker is saying is an accepted part of strategic one-upmanship at conferences, we felt it unwise to introduce this possibility of misclassification bias. In addition, a consensus of experienced speakers (grade $\mathrm{C}$ evidence) suggests that participants can be as inattentive as they wish, as long as they are quiet.

We recognize that the line between physiologically normal

Table 1: Interpretation of physicians' behaviours related to cellular telephone use at medical conferences and localization of frontal lobe dysfunction

\begin{tabular}{|c|c|c|}
\hline Behaviour & Interpretation & Localization \\
\hline Forgets to mute or turn off phone & $\begin{array}{l}\text { Prospective memory } \\
\text { impairment }\end{array}$ & Dorsolateral prefrontal \\
\hline Chooses not to mute or turn off phone & Social conduct disorder & Orbitofrontal \\
\hline $\begin{array}{l}\text { Hears phone ring but cannot be } \\
\text { bothered to answer }\end{array}$ & Apathy & Anterior cingulate \\
\hline $\begin{array}{l}\text { Unable to answer phone within first } \\
3 \text { rings }\end{array}$ & Psychomotor slowing & Mixed \\
\hline $\begin{array}{l}\text { Answers phone loudly while still } \\
\text { in the room }\end{array}$ & $\begin{array}{l}\text { Social conduct disorder, } \\
\text { possible deafness }\end{array}$ & Orbitofrontal \\
\hline $\begin{array}{l}\text { Fumbles for prolonged period } \\
\text { to answer phone }\end{array}$ & Frontal apraxia & Mixed \\
\hline Calls out “Hey dollface!” & Sexual disinhibition & Orbitofrontal \\
\hline
\end{tabular}


impaired social conduct and that which is pathological can be fine. One of us once gave a dinner talk to an audience of I4, 2 of whom groped each other through about half the presentation. Intense hormonal influences can overwhelm social behaviour, but these effects generally fade, so such activity should probably be labelled pathological only if it persists say past age 17 .

An important strength of our study is that our observations were not limited to audience members. Many of the aberrant behaviours were also exhibited by speakers. An invitation to speak provides brain-damaged individuals an opportunity to display poor social conduct and impaired executive function (even when speaking to executives). Notable among these behaviours was lack of planning, as evidenced by the use of unreadable, "busy" slides. Lack of self-monitoring and self-inhibition was commonly demonstrated by one speaker who repeated most of what the previous speaker had just said; this deficit is not mitigated by first saying "I don't want to spend time on what we've all just heard." Some speakers exhibited lack of planning and lack of empathy, as evidenced by their use of too many slides, which resulted in their speaking too quickly and cramming too much in. Severe frontal lobe dysfunction was demonstrated by speakers who went over time: even in a room with only roo people, going over by as little as 5 minutes wastes a half-day of collective effort. Localization of this behaviour is complex; we acknowledge, too, that deliberate provocation cannot always be ruled out.
Medical conferences represent immense opportunities for the study of frontal lobe dysfunction. This paper inaugurates the field of neuroconferencology, a topic about which we are glad to speak, given suitable invitation ... by email. Please don't call.

Competing interests: None admitted to by either author.

Contributions: Kenneth Rockwood conceived of the idea and wrote the first draft of the paper. Howard Chertkow corrected Rockwood's faulty understanding of frontal lobe function and edited out the truly snotty bits. Both authors approved the final draft.

\section{Kenneth Rockwood MD \\ Geriatrician \\ Halifax, NS \\ Howard Chertkow MD \\ Cognitive neurologist \\ Montréal, Que.}

\section{REFERENCES}

I. Rockwood K, Patterson CJ, Hogan DB. Nodding and napping in medical lectures: an instructive systematic review. CMAJ 2005;173:1502-3.

2. Rockwood K, Hogan DB, Patterson CJ. Incidence of and risk factors for nodding off at scientific sessions. CMAJ 2004; I7I:I443-5.

3. Frank C, MacKnight C. Holiday waistline. Time to consensus: the effect of the stomach on consensus decision-making at large conferences. CMAJ 2006;175: I569-7I.

4. Dubois B, Slachevsky A, Litvan I, et al. The FAB: a Frontal Assessment Battery at bedside. Neurology 2000;55:I62I-6.

\section{Getting to the heart of the Ho Ho}

What's funny and what's not? Assessing whether or not an article is humorous and suitable material for the CMAJ Holiday Review can be fraught with difficulty. What tickles the funny bone of one reviewer brings a groan of despair from another. This year, we decided to take a more scientific approach to our deliberations and employed a Likert scale to determine exactly how entertaining our reviewers found each article. Furthermore, we devised an innovative LOL (laughed out loud) scale to determine, well, whether we drew strange looks from our cubicle mates (above and beyond the ordinary).

Our job was made more difficult by the unprecedented number of submissions we garnered this year: 43 in all.

CMA/thanks the judges: Managing Editor, Patricia Lightfoot; News Editor, Wayne Kondro; Manuscript Editors, Wendy Carroll, Jesse Craig and Kate Schissler; (former) Manager, Submissions and Peer Review, Peggy Robinson; and Editorial Coordinator, Erin Driscoll.s. We hope you enjoy the gth annual CMAJ Holiday Review. — Barbara Sibbald, CMAJ 